\title{
A Terra na Alimentação de Pintos (")
}

\author{
A. P. TRIVELIN \\ Assistente \\ Escola Superior de Agricultura "Luiz de Queiroz" \\ Universidade de São Paulo
}

\begin{abstract}
INDICE

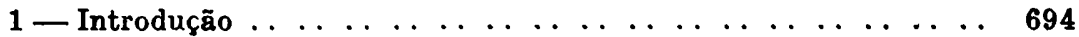

2 - Plano c Material . . . . . . . . . . . . . . . . . . . . . 694

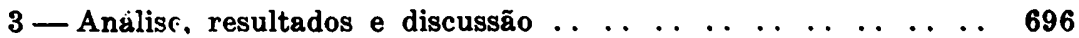

4 - Contraprova . . . . . . . . . . . . . . . . . . . . . . . 700

5 - Conclusões . . . . . . . . . . . . . . . . . . . . . . 701

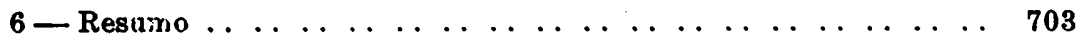

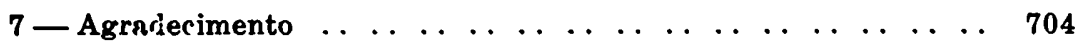

8 - Abstract . . $\ldots \begin{array}{lllllllllllllllll} & \ldots & \ldots & \ldots & \ldots & \ldots & \ldots & \ldots & \ldots & \ldots & \ldots & \ldots & \ldots & \ldots & \ldots & 704\end{array}$

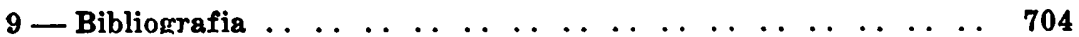

(*) Trabalho da Secção de Avicultura.
\end{abstract}




\section{1 - INTRODUÇÃO}

A recente descoberta do fator proteico animal (F. P. A.) deu logar a inúmeras pesquizas no terreno da nutrição das aves, visando determinar novos fatores de crescimento.

Assim, MCGINNIS, STEVENS (1947), depois de terem estudado as fezes de galinhas como fonte de fator de crescimento, deduziram que sua origem era microbiana. Posteriormente, MCGINNIS, STEPHENSON, CARVER, GRAHAM e LEWIS (1948) descobriram que o Bacillus subtilis continha um ou mais fatores de crescimento. Como era muito provável sua ocorrência no solo, resolveram verificar se a introdução de terra na ração supriria as necessidades do fator animal (2).

Coletaram terra de um campo que não recebia estêrco há 3 anos; após a remoção da camada superficial retiraram-na de uma profundidade de 2 polegadas e adicionaram $1 \%$ à ração. Utilizaram pintos oriundos de galinhas alimentadas com deficiência do fator proteico animal (F. P. A.), que por sua vez foram alimentados com uma ração onde não havia proteina animal. Após três semanas o lote testemunha, que não recebeu terra, apresentava não sòmente uma mortalidade maior, como um crescimento muito menor (91 e 112 grs.) em relação áquele que recebera apenas como suprimento (133 e 141 grs.). Estes resultados se mostraram altamente significativos pela análise estatística.

Dada a relevância do problema pelo seu grande valor se aplicado na prática criatória, resolvemos conduzir uma experiência a fim de nos certificarmos da sua extensão e aplicabilidade.

\section{2 - PLANO E MATERIAL}

Foram separados para a experiência 150 pintos fêmeas, da raça Rhode Island Red, da mesma idade e de poucos dias, com os quais formamos 6 lotes em 2 grupos de 3, tão homogêneos quanto possível.

A escolha de pintos de alguns dias de idade pareceu-nos mais favorável à experiência, por permitir-nos eliminar alguns mais fracos, diminuindo a principal fonte de variação dentro do lote. 
Nasceram em 2 de agosto, época ainda favorável a um desenvolvimento normal e durante o decorrer da experiência estiveram debaixo das mesmas condições.

Os pintos de cada lote receberam um anel de matéria plástica de uma côr particular. A princípio foram criados em criadeiras baterias (2 semanas), passando depois para casa criadeira, onde permaneceram até o fim da experiência, inspeccionados diàriamente. A primeira pesada foi feita em 12-8-49 e as seguintes, semanalmente até a 6a. pesada, que foi a última na presente experiência.

Damos no quadro I as rações utilizadas para cada lote. A ração A é uma ração comum, semelhante às outras usadas normalmente na Seç̧ão de Avicultura, da qual se esperava um crescimento satisfatório. A ração $B$, fornecida ao lote $B$, difere apenas por conter $2 \%$ de terra de cultura, que há algum tempo não recebia adubação. Finalmente, na ração $\mathrm{C}$, ministrada ao lote $\mathrm{C}$, substituimos os $10 \%$ de farinha de carne por igual percentagem de farelo de amendoim, para mantermos aproximadamente o mesmo teor de proteina bruta. Com essa substituição, suprimimos o fator proteico animal (F. P. A.) da ração C e mantivemos os $2 \%$ de terra, a fim de observar a presença ou ausência de fator de crescimento.

Adotamos para a colheita da terra, a mesma técnica empregada pelos autores americanos (2).

QUADRO I

\begin{tabular}{|c|c|c|c|}
\hline \multirow{2}{*}{ Ingredientes } & \multicolumn{3}{|c|}{ Rações } \\
\hline & $\mathbf{A}$ & B & $\mathbf{C}$ \\
\hline $\begin{array}{l}\text { Milho } \\
\text { Farinha de carne } 50 \% \\
\text { Farelo de amendoim } \\
\text { Farelo de algodão } \\
\text { Farelinho de arroz } \\
\text { Far. de sabugo, bem moido } \\
\text { Farinha de ostra } \\
\text { Sal } \\
\text { Terra }\end{array}$ & $\begin{array}{r}50 \mathrm{ks} . \\
10 \mathrm{ks} . \\
10 \mathrm{ks} . \\
10 \mathrm{ks} . \\
10 \mathrm{ks} . \\
10 \mathrm{ks} . \\
2 \mathrm{ks} . \\
0,700 \mathrm{ks} . \\
-\end{array}$ & $\begin{array}{r}50 \mathrm{ks} . \\
10 \mathrm{ks} . \\
10 \mathrm{ks} . \\
10 \mathrm{ks} . \\
10 \mathrm{ks} . \\
10 \mathrm{ks} . \\
2 \mathrm{ks} . \\
0,700 \mathrm{ks} \\
2 \mathrm{ks} .\end{array}$ & $\begin{array}{l}50 \mathrm{ks} . \\
\overline{20} \mathrm{ks} . \\
10 \mathrm{ks} . \\
10 \mathrm{ks} . \\
10 \mathrm{ks} . \\
2 \mathrm{ks} . \\
0,700 \mathrm{ks} . \\
2 \mathrm{ks} .\end{array}$ \\
\hline$\%$ de proteina bruta & 20,0 & 20,0 & 19,6 \\
\hline
\end{tabular}




\section{3 - ANALISE, RESULTADOS E DISCUSSÃO}

Os dados colhidos e analisados estão reunidos no quadro II, onde podemos observar que a diferença entre as médias dos lotes A e B, no primeiro grupo foi sempre pequena. Isto permite-nos formular a suposição de que a inclusão de $2 \%$ de terra à uma ração normal não trouxe vantagem, pois, não houve aumento satisfatório de pêso. $\mathrm{O}$ mesmo se deu no segundo grupo, onde a diferença entre as médias dos lotes $A$ e $B$, não foi suficiente para considerá-la como prática. A média do lote $C$, em ambos os grupos, mostrou-se inferior às dos lotes $\mathrm{A}$ e $\mathrm{B}$, constatando-se uma diferença de 75,1 gramas no primeiro grupo e de 25,5 gramas no segundo, em relação à média do lote $\mathrm{A}$, na sexta pesada. Essas observações, tiradas de simples inspecção de números, são confirmadas pelo t-teste, cujos valores de t estão inclusos no quadro III. Por êle, constatamos nenhuma significância estatística entre as médias dos lotes $\mathrm{A}$ e $\mathrm{B}$, nos dois grupos. Embora, a média do lote $\mathrm{B}$ fosse superior à do $\mathrm{A}$, de algumas gramas, a análise permite-nos considerá-los idênticos, o que demonstra nenhuma influência dos $2 \%$ de terra adicionado à ração $\mathrm{A}$.

O lote $\mathrm{C}$ revelou-se estatisticamente inferior aos lotes $\mathrm{A} e$ $\mathrm{B}$, em ambos os grupos, pois, sua média comparada com às dêstes lotes, mostrou-se estatìsticamente significante no primeiro grupo, em relação a $\mathrm{A}$, desde a $5 \mathrm{a}$. pesada e em relação a $\mathrm{B}$, a partir da terceira. No segundo grupo, essa significância estatística apareceu na 3a. pesada, em relação a $\mathrm{B}$ e sòmente na $6 \mathrm{a}$. pesada é que se mostrou duvidosa, relativamente à média do lote $\mathrm{A}$. Deste modo, chegamos a conclusão que os $2 \%$ de terra não foi portador de fator ou fatores de crescimento que pudessem dispensar os $10 \%$ de farinha de carne da ração $\mathrm{A}$.

A mortalidade constatada foi a seguinte:

$\begin{array}{lccc} & 1^{\circ} \text {. Grupo } & 2^{\circ} \text {. Grupo } & \text { Média } \\ \text { Lote A } & 0 \% & 0 \% & 0 \% \\ \text { Lote B } & 16 \% & 4 \%\left(^{*}\right) & 10 \% \\ \text { Lote C } & 12 \% & 8 \% & 10 \%\end{array}$

donde observamos que nesta experiência a mortalidade dos pintos que ingeriram terra foi maior do que a daqueles que não a receberam. Entretanto, como está dentro dos limites normais, necessitaria de confirmação em outras experiências.

(*) $4 \%$ corresponde a um pinto. 


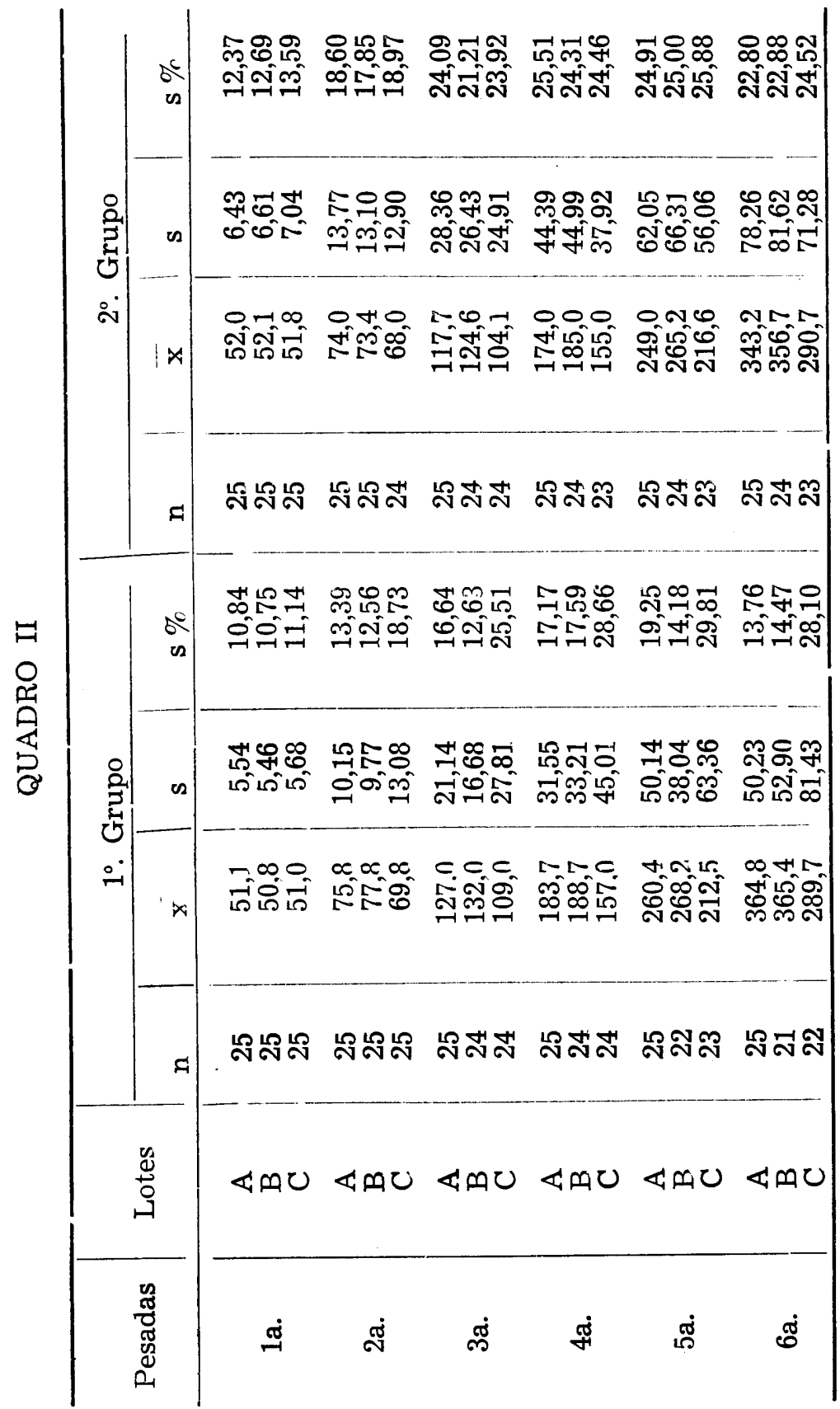


QUADRO III

Valores de $\mathrm{t}$

\begin{tabular}{|c|c|c|c|}
\hline Pesadas & & $1^{\circ}$. Grupo & $2^{\circ}$. Grupo \\
\hline 1a. & $\begin{array}{l}A / B \\
A / C \\
B / C\end{array}$ & $\begin{array}{r}0,19 \\
-0,06 \\
-\quad 0,13\end{array}$ & $\begin{array}{r}0,05 \\
0,10 \\
0,16\end{array}$ \\
\hline $2 a$. & $\begin{array}{l}\mathrm{A} / \mathrm{B} \\
\mathrm{A} / \mathrm{C} \\
\mathrm{B} / \mathrm{C}\end{array}$ & $\begin{array}{r}0,71 \\
1,82 \\
2,46\end{array}$ & $\begin{array}{l}0,16 \\
1,57 \\
1,46\end{array}$ \\
\hline 3a. & $\begin{array}{l}\mathrm{A} / \mathrm{B} \\
\mathrm{A} / \mathrm{C} \\
\mathrm{B} / \mathrm{C}\end{array}$ & $\begin{array}{l}-0,92 \\
2,54 \\
3,47\left(^{*}\right)\end{array}$ & $\begin{array}{l}-0,88 \\
1,79 \\
2,76(*)\end{array}$ \\
\hline $4 a$. & $\begin{array}{l}\mathrm{A} / \mathrm{B} \\
\mathrm{A} / \mathrm{C} \\
\mathrm{B} / \mathrm{C}\end{array}$ & $\begin{array}{l}-0,54 \\
2,39 \\
2,77\left(^{*}\right)\end{array}$ & $\begin{array}{r}0,86 \\
1,60 \\
2,47\end{array}$ \\
\hline $5 a$. & $\begin{array}{l}\mathrm{A} / \mathrm{B} \\
\mathrm{A} / \mathrm{C} \\
\mathrm{B} / \mathrm{C}\end{array}$ & $\begin{array}{r}0,61 \\
2,89(*) \\
3,59(*)\end{array}$ & $\begin{array}{c}0,88 \\
1,90 \\
2,71 \quad(*)\end{array}$ \\
\hline $6 a$. & $\begin{array}{l}\mathrm{A} / \mathrm{B} \\
\mathrm{A} / \mathrm{C} \\
\mathrm{B} / \mathrm{C}\end{array}$ & $\begin{array}{l}0,04 \\
3,74\left(^{*}\right) \\
3,63(*)\end{array}$ & $\begin{array}{r}0,59 \\
2,43 \\
\mathbf{2 , 9 5}(*)\end{array}$ \\
\hline
\end{tabular}

(*) Significante.

Como no decorrer da experiência alguns pintos começaram apresentar, a partir da 3a. pesada, pêsos muito discordantes em relação ao conjunto, resolvemos eliminar essas variáveis e procedemos a nova análise.

Os resultados estão expressos no quadro IV, onde também encontramos as variaveis eliminadas para efeitos dêsse novo cálculo. Observamos, ainda, que a diferença entre as médias dos lotes $\mathrm{A}$ e $\mathrm{B}$, continuou pequena e que a média do lote $\mathrm{C}$ persistiu sempre bem inferior àquelas dos outros 2 lotes, em ambos os grupos. Os valores de $t$, expressos no quadro V, resultantes da comparação dessas médias, confirmam a conclusão chegada anteriormente, segundo a qual, os $2 \%$ de terra, retirada de um campo de cultura, que não se estercou por algum tempo, não introduziu fator ou fatores de crescimento que pudessem compensar a substituição de $10 \%$ de farinha de carne, por -igual percentagem de farelo de amendoim. 


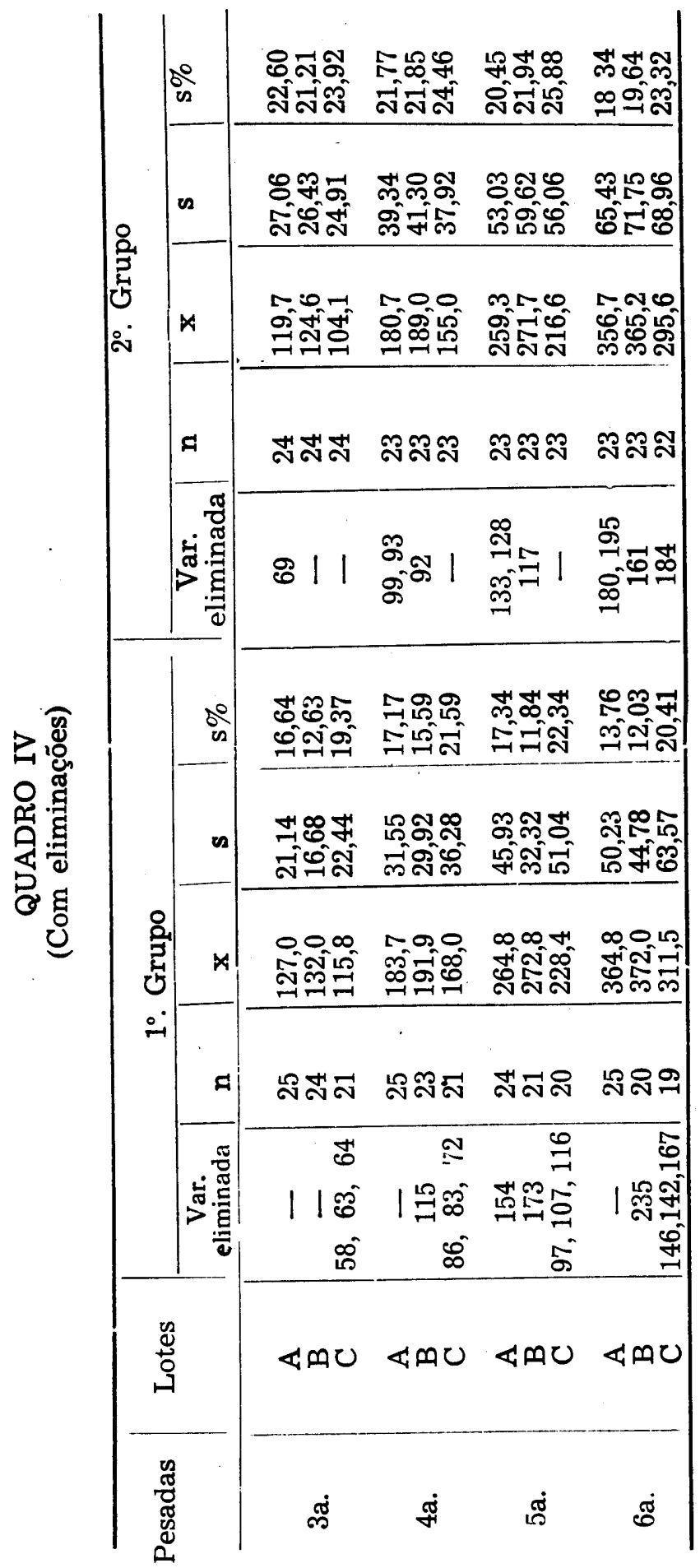


A ligeira vantagem conseguida pelo lote $B$ em relação a $A$, não comprovada estatìsticamente, dá-nos o ensejo de supôr que tenha sido causada pela introdução de sais minerais que acompanharam a terra. Infelizmente, ao se planejar a presente experiência não foi organizado um quarto lote que deveria receber uma ração isenta de F. P. A. e também de terra. Este, deveria ser tomado como termo de comparação ao lote $\mathrm{C}$ (ração isenta de F. P. A. e com $2 \%$ de terra de cultura), motivo pelo qual, não podemos contestar os resultados chegados pelos autores americanos (2).

QUADRO V

Valores de $t$

(Com eliminações)

\begin{tabular}{|c|c|c|c|}
\hline Pesadas & & $1^{\circ}$. Grupo & $2^{\circ}$. Grupo \\
\hline 3a. & $\begin{array}{l}A / B \\
A / C \\
B / C\end{array}$ & $\begin{array}{l}-0,92 \\
1,73 \\
2,72\left(^{*}\right)\end{array}$ & $\begin{array}{l}-0,63 \\
2,08 \\
2,76 \text { (*) }^{*}\end{array}$ \\
\hline $4 a$. & $\begin{array}{l}A / B \\
A / C \\
B / C\end{array}$ & $\begin{array}{r}0,92 \\
1,55 \\
2,37\end{array}$ & $\begin{array}{r}0,70 \\
2,25 \\
2,90 \text { (*) }^{*}\end{array}$ \\
\hline 5a. & $\begin{array}{l}A / B \\
A / C \\
B / C\end{array}$ & $\begin{array}{l}-0,68 \\
2,46 \\
3,31 \quad(*)\end{array}$ & $\begin{array}{r}0,74 \\
2,65 \text { (*) }^{*} \\
3,81 \text { (*) }^{*}\end{array}$ \\
\hline 6a. & $\begin{array}{l}A / B \\
A / C \\
B / C\end{array}$ & $\begin{array}{r}0,51 \\
3,01 \text { (*) }^{*} \\
3,42 \text { (*) }^{*}\end{array}$ & $\begin{array}{r}0,42 \\
3,05 \text { (*) }^{*} \\
3,32 \text { (*) }^{*}\end{array}$ \\
\hline
\end{tabular}

(*) Significante.

\section{4 - CONTRAPROVA}

Para confirmação dos resultados obtidos resolvemos repetir a experiência com outra ração e utilizando também terra de galinheiro, onde supúnhamos mais fácil de encontrar fator ou fatores de crescimento, si êstes fossem de fato encontrados nas fézes e devessem passar ao solo. 


\section{QUADRO VI}

\begin{tabular}{|c|c|c|c|c|}
\hline \multirow{2}{*}{ Ingredientes } & \multicolumn{4}{|c|}{ Rações } \\
\hline & $\mathbf{A}$ & B & $\mathbf{C}$ & $\mathbf{D}$ \\
\hline $\begin{array}{l}\text { Milho moido } \\
\text { Farinha de carne } \\
\text { Farelo de amendoim } \\
\text { Farelo de algodão } \\
\text { Farelinho de arroz } \\
\text { Farinha de ostra } \\
\text { Sal fino } \\
\text { Terra de cultura } \\
\text { Terra de galinheiro }\end{array}$ & $\begin{array}{l}60 \mathrm{ks} . \\
15 \mathrm{ks} . \\
\overline{15} \mathrm{ks} . \\
10 \mathrm{ks} . \\
2 \mathrm{ks} \\
0,7 \mathrm{ks} . \\
2 \mathrm{ks} . \\
-\end{array}$ & $\begin{array}{l}60 \mathrm{ks} . \\
15 \mathrm{ks} . \\
\overline{15} \mathrm{ks} . \\
10 \mathrm{ks} . \\
2 \mathrm{ks} . \\
0,7 \mathrm{ks} . \\
2 \mathrm{ks} . \\
\end{array}$ & $\begin{array}{l}60 \mathrm{ks} . \\
15 \mathrm{ks} . \\
\overline{15} \mathrm{ks} . \\
10 \mathrm{ks} . \\
2 \mathrm{ks} . \\
0,7 \mathrm{ks} . \\
\overline{2} \mathrm{ks} .\end{array}$ & $\begin{array}{l}60 \mathrm{ks} . \\
\overline{15} \mathrm{ks} . \\
15 \mathrm{ks} \\
10 \mathrm{ks} . \\
2 \mathrm{ks} . \\
0,7 \mathrm{ks} \\
2 \mathrm{ks}\end{array}$ \\
\hline$\%$ de proteina bruta & 20,6 & 20,6 & 20,6 & 20,0 \\
\hline
\end{tabular}

Quatro rações foram organizadas segu ndo o quadro VI. A experiência foi iniciada em 23-9-49, quando os pintos já contavam 20 dias de idade, formando-se 4 lotes de 40 pintos da raça Leghorn. A época já era um pouco imprópria para criação e não foi possível uma uniformidade maior do que a obtida.

Em virtude de, na terceira e na quarta semanas, ter havido mistura de alguns pintos, como podemos constatar observando o quadro VII, tal acontecimento não permitiria uma análise estatística real, porém, como foram poucos, não afetaram de todo o resultado. As médias demonstram que a incorporação de terra, quer de galinheiro, quer de cultura, não apresenta muito valor, desde que a ração contenha $10 \%$ de farinha de carne.

A análise estatística não daria diferença significativa entre os lotes $\mathrm{A}, \mathrm{B}$ e $\mathrm{C}$ e provàvelmente, daria entre êstes e $\mathrm{D}$, que não têm o fator animal.

\section{5 - CONCLUSÓES}

Duas experiências realizadas em Piracicaba, com adição de $2 \%$ de terra em ração de pintos em crescimento, uma das quais (1a. experiência) com resultados analizados, não revelaram a existência de fator ou fatores de crescimento no solo donde foram retiradas as amostras, que pudessem dispensar os $10 \%$ de farinha de carne de uma ração comum. 


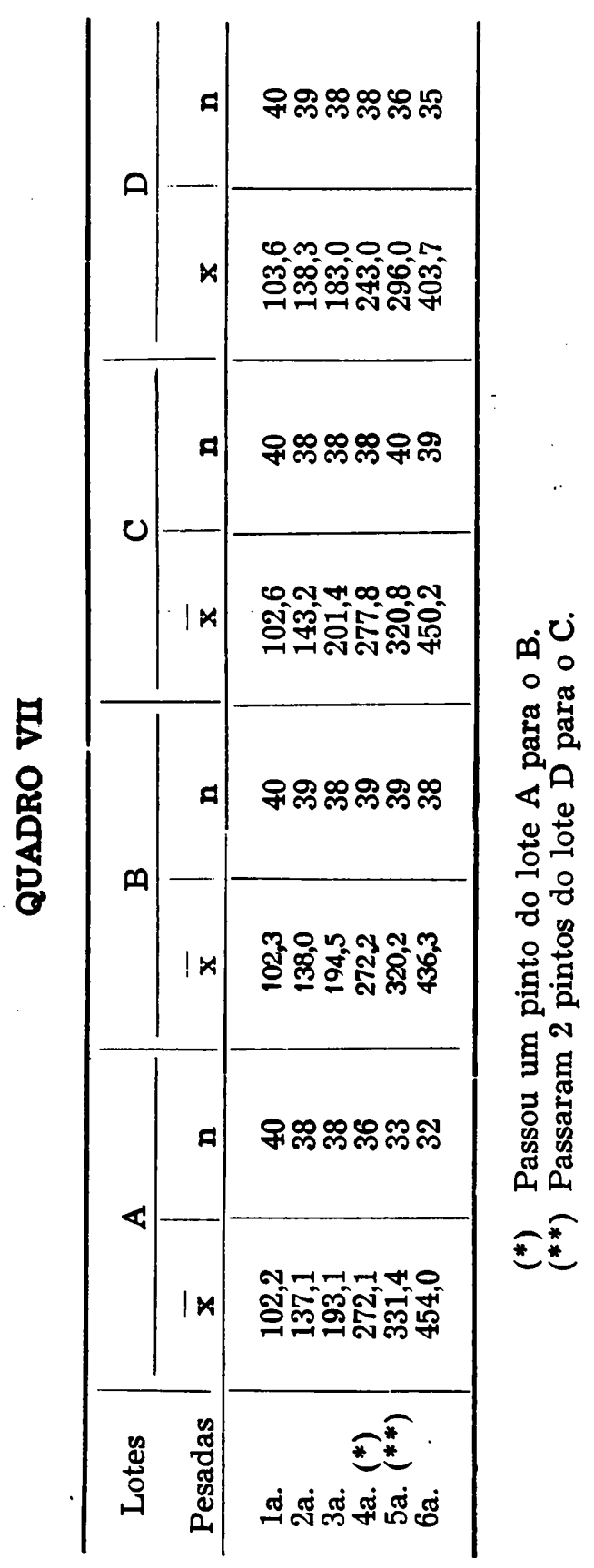


Embora houvesse certa mistura de pintos na contraprova realizada (2a. experiência), foi possível perceber-se que a maior mortalidade daqueles que receberam terra na primeira experiência foi provàvelmente, devida ao acaso.

A ligeira vantagem conseguida pelo lote $B$, em relação a A, nos 2 grupos da primeira experiência, embora não constata da estatìsticamente, talvez seja devida a um teor de sais minerais algo mais elevado (?) conseguido pela incorporação de $2 \%$ de terra de cultura à ração, ou provàvelmente, à presença de fator ou fatores de crescimento que não puderam agir satisfatòriamente, em virtude de já existir na ração bôa percentagem de farinha de carne (F. P. A.).

Não sendo feito um lote que deveria receber uma ração isenta de F. P. A. e de terra, a fim de servir como termo de comparação aos lotes $\mathrm{C}$ e $\mathrm{D}$, respectivamente, da primeira e segunda experiência, os resultados por nós obtidos não permitem contestar os conseguidos pelos autores americanos (1).

\section{6 - RESUMO}

Com 150 pintos femeas da raça Rhode Island Red, formamos 6 lotes em 2 grupos de 3. As rações empregadas na alimentação dêsses pintos estão inclusas no Quadro I, onde constatamos que a ração $A$, fornecida ao lote $A$, é uma ração comum, normalmente empregada na Seção de Avicultura. A ração $B$, fornecida ao lote B, difere da A, por conter $2 \%$ de terra de cultura, que desde algum tempo não recebia estérco. Finalmente, na ração $C$, ministrada ao lote $C$, substituimos os $10 \%$ de farinha de carne por igual percentagem de farelo de amendoim a fim de suprimirmos o F. P. A. e mantivemos os $2 \%$ de terra de cultura.

Constituiu objetivo dessa experiência saber se a terra como elemento portador de fator ou fatores de crescimento, poderia dispensar, satisfatòriamente, o emprêgo de $10 \%$ de farinha de carne numa ração comum.

Os valores de $t$ resultantes da comparação das médias dos citados lotes estão expressos no Quadro III. Por êles verificamos que a incorporação de terra de cultura na proporção de $25 \%$, à uma ração normal, não determinou aumento satisfatório de pêso. Embora, a média do lote $B$ fosse superior a de $A$ de algumas gramas, nos 2 grupos, estatìsticamente, essa ligeira vantagem não foi comprovada. A análise permite-nos considerá-los iguais. O lote $\mathrm{C}$ mostrou-se sempre inferior ao $\mathrm{A}$ e $\mathrm{B}$, nos dois grupos.

Com a eliminação de algumas variáveis que se mostraram muito afastadas da média, fizemos a nova análise (Quadro IV) 
e os novos valores de $t$ (Quadro V) confirmaram a conclusão chegada anteriormente. Para comprovação da mortalidade ocorrida nos lotes $\mathrm{B}$ e $\mathrm{C}$, que foi de 16 e $4 \%$, de 12 e $8 \%$, respectivamente, no primeiro e segundo grupo, realizamos uma nova experiência, utilizando pintos da raça Leghorn.

Com êles formamos 4 lotes de 40 . Empregamos, além de terra de cultura, terra de galinheiro, onde supúnhamos ser mais fácil de encontrar fator ou fatores de crescimento (Quadro VI).

Como houvesse mistura de alguns pintos (Quadro VII) os dados reunidos não nos permitiriam uma análise estatística real, contudo, como foram poucos, o resultado não foi de todo afetado. Pela inspeção das médias, chegámos a conclusão de que a incorporação de terra, quer de cultura, quer de galinheiro, a uma ração normal para pintos, contendo $10 \%$ de farinha de carne não apresenta muito valor. Por esta segunda experiência podemos também concluir que a mortalidade verificada na primeira, provavelmente foi devida ao acaso.

\section{7 - AGRADECIMENTO}

O autor agradece ao Prof. Alcides Di Paravicini Torres pelas críticas e sugestões formuladas.

\section{8 - ABSTRACT}

The present experiment deals with the influence of soil on chick growth. Three lots named A (usual ration), B (usual ration and $2 \%$ of soil) and $\mathrm{C}$ (ration without meat meal and and with $2 \%$ of soil) were compared. The results obtained can be summarized as follows :

a) Lot $C$ was inferior to lots $A$ and $B$ and the difference proved to be statistically significant.

b) Better results were obtained with lot $B$ in comparison with lot $A$ but the methods of analysis used could not prove this differences to be statistically significant.

c) The results obtained seems to indicate some factors for chick growth present in lot $B$. The author thinks the mineral salts of the soil could be responsible for the difference observed.

\section{9 - BIBLIOGRAFIA}

1-GRANER, E. A. (1951). Como Aprender Estatística. Cia. Melhoramentos de São Paulo (Em impressão).

2-STEPHENSON, E. L., JAMES MCGINNIS, W. D. GRAHAM e J. S. CARVER (1948). Effect of soil on chick growth. Poultry Science, Vol. XXVII: 827-828. 


\section{Experiências de Engorda de Frangos (*)}

\section{II}

Prof. A. P. TORRES e engenheirando J. M. SANTOS

Escola Superior de Agricultura "Luiz de Queiroz"

INDICE

1 —Introdução $\ldots \ldots \ldots \ldots$

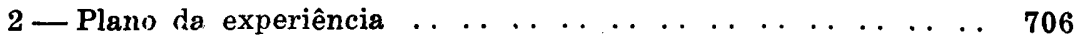

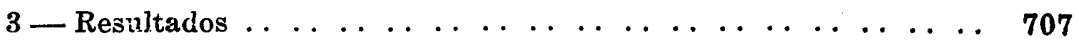

4 - Discussão $\ldots \ldots \ldots \ldots$

5 - Resumo e conclusões $\ldots \ldots \ldots \ldots$

6 - Abstract . . . . . . . . . . . . . . . . . . . . . . . . . . . . 710

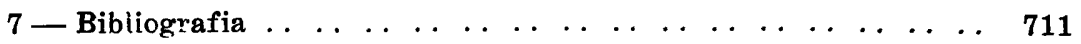

(*) Trabalho da Seção de Avicultura e Cunicultura 


\section{INTRODUÇÃO}

Uma primeira experiência realizada na Seção de Avicultura e Cunicultura, da E. S. A. "Luiz de Queiroz", U. S. P., por TORRES \& TRIVELIN (1), revelou que o maior aumento de pêso no preparo final de frangos para o mercado - processo entre nós chamado "engorda" - se verificava nos primeiros sete dias e lhes pareceu que 14 dias seria um periodo grande e anti-econômico, pois nesse período a intensidade de aumento de pêso já está bem diminuida.

JULL \& MAN (2) acham que 10 dias é um período conveniente para raças mais pesadas e 14 para as raças leves, o que é admitido por outros autores.

Finalmente EWING (3) chama atenção para o fato de certos alimentos produzirem uma engorda mais rápida, em 7 dias, não produzindo aumentos posteriormente, fato observado por TORRES \& TRIVELIN (1), enquanto outros alimentos continuam a produzir aumentos até 14 dias.

\section{PLANO DA EXPERIENCIA}

$\mathrm{Na}$ presente experiência foram usados trinta frangos da raça Rhode I. Red, com um pêso médio de 1.745 gs., tendo um sido eliminado na quarta pesagem por motivo de moléstia (leucose), ficando 29 .

Essas aves foram colocadas 2 a 2, em 15 gaiolas de nosso biotério, recebendo a seguinte ração de alimentos comuns na alimentação de aves, nesta região:

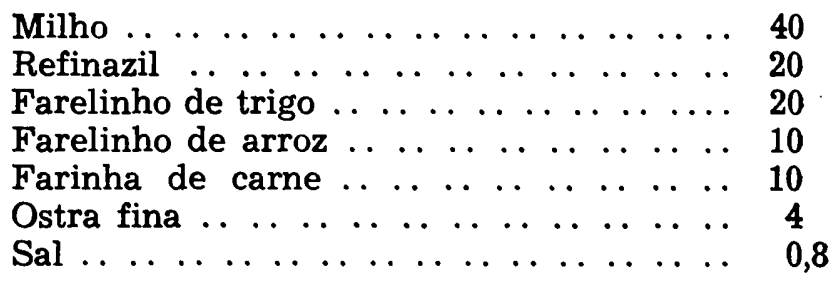

Esta ração, que contêm aproximadamente $17,0 \%$ de proteina bruta não apresenta particularidade especial para ser recomendada. Foi moida finamente, e umidecida no momento de ser empregada afim de homogenizá-la.

O consumo de ração foi de $56 \mathrm{ks}$. em 22 dias, dando portanto uma média diária de 88 gs. por cabeça. 
Cada frango recebeu um número e foi pesado individualmente. A experiência teve início no dia 31-3-50, quando foi feita a 1a. pesagem; a 2a. pesagem verificou-se quatro dias após, e as demais cada dois dias, perfazendo um total de 11 pesagens e 10 períodos.

Determinou-se posteriormente a percentagem de aumento verificado, em cada período, sôbre o pêso inicial nesse intervalo.

Foram determinados os aumentos médios nos diferentes períodos para se verificar a economia do ganho médio.

Estudou-se a variação individual de aumento $\%$, sôbre o pêso inicial afim de mostrar a variação decorrente da individualidade.

Finalmente, com os dados obtidos, os AA. construiram um gráfico (́pág. 709) que permite ao leitor observar o proporção de frangos que deixa de crescer e chega mesmo a perder pêso, à medida que progride a engorda.

\section{RESULTADOS}

No quadro abaixo apresentam resumidamente os resultados obtidos com as pesagens. $O$ pêso inicial foi de $50.600 \mathrm{gs}$. para 29 pintos, com média de 1.745 e o final 65.700 gs. com 2.266 de média, dando um aumento médio de 521 gs., que corresponde a $30 \%$ do pêso inicial: Este resultado é satisfatório, embora pudesse ser superado. Observe-se contudo que o mesmo pêso é obtido em 16 dias (67.750), o que confirma ser inutil prolongar a engorda além dêsse período.

QUADRO I

\begin{tabular}{l|r|r|r|r}
\hline & \multicolumn{2}{|c|}{ Pêso } & \multicolumn{2}{c}{ Aumentos } \\
\cline { 2 - 5 } Período & Total & Médio & Total & $\%$ \\
\hline & & & & \\
\cline { 5 - 5 } Aos 4 dias & 55.050 & 1.898 & 4.450 & 8.79 \\
Aos 6 dias & 57.550 & 1.984 & 2.500 & 4.54 \\
Aos 8 dias & 59.000 & 2.094 & 1.450 & 2.52 \\
Aos 10 dias & 61.700 & 2.128 & 2.700 & 4.58 \\
Aos 12 dias & 63.450 & 2.188 & 1.750 & 2.84 \\
Aos 14 dias & 64.600 & 2.228 & 1.150 & 1.81 \\
Aos 16 dias & 65.750 & 2.267 & 1.150 & 1.78 \\
Aos 18 dias & 66.700 & 2.300 & 950 & 1.44 \\
Aos 20 dias & 66.250 & 2.284 & -450 & -0.67 \\
Aos 22 dias & 65.700 & 2.266 & -550 & -0.82 \\
\hline
\end{tabular}


Em 12 dias obteve-se um aumento médio de 443 gs. que corresponde a $25,4 \%$ do pêso inicial e aos 14 dias 483 gs. ou 27,7 do pêso inicial.

A uniformidade dos aumentos finais observado é razoável como se pode observar do quadro abaixo :

QUADRO II

Classificação final dos aumentos individuais expressos em porcentagens

\begin{tabular}{|c|c|c|c|c|c|}
\hline \multirow{2}{*}{ 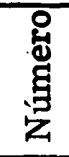 } & \multicolumn{2}{|c|}{$\%$ de aumento } & \multirow{2}{*}{ Número } & \multicolumn{2}{|c|}{$\%$ de aumento } \\
\hline & Em 12 dias & Em 22 dias & & Em 12 dias & Em 22 dias \\
\hline $\begin{array}{r}462 \\
202 \\
255 \\
154 \\
358 \\
468 \\
419 \\
441 \\
257 \\
99 \\
254 \\
334 \\
245 \\
315 \\
472\end{array}$ & $\begin{array}{l}36,6 \\
46,2 \\
37,5 \\
31,2 \\
25,9 \\
30,0 \\
36,4 \\
30,3 \\
28,9 \\
25,7 \\
25,0 \\
24,3 \\
27,1 \\
24,3 \\
25,0\end{array}$ & $\begin{array}{l}49,97 \\
46,15 \\
43,74 \\
43,73 \\
40,74 \\
39,96 \\
39,39 \\
36,36 \\
31,57 \\
31,42 \\
30,55 \\
29,72 \\
29,72 \\
29,71 \\
27,76\end{array}$ & $\begin{array}{r}317 \\
414 \\
89 \\
450 \\
440 \\
492 \\
413 \\
238 \\
201 \\
424 \\
485 \\
335 \\
474 \\
259\end{array}$ & $\begin{array}{l}21,6 \\
26,7 \\
23,7 \\
20,9 \\
17,5 \\
21,9 \\
21,6 \\
21,4 \\
21,1 \\
21,1 \\
23,5 \\
23,1 \\
22,2 \\
18,2\end{array}$ & $\begin{array}{l}27,27 \\
26,64 \\
26,30 \\
25,57 \\
25,00 \\
24,99 \\
24,31 \\
23,80 \\
23,67 \\
23,67 \\
23,52 \\
23,07 \\
22,22 \\
18,18\end{array}$ \\
\hline
\end{tabular}

\section{DISCUSSAOO}

Pode-se observar pelo exame do Quadro I que o aumento total verificado entre o $12^{\circ}$. e o $16^{\circ}$. dia, corresponde a 2,300 de frango, que, ao preço médio de $\operatorname{Cr} \$ 16,00 \circ \mathrm{k}$., representará $\mathrm{Cr} \$ 36,80$. Si os 29 frangos comerem na base de $88 \mathrm{gs}$. por dia e por cabeça, consumirão neste periodo $10,100 \mathrm{ks}$. de de ração que ao preço de $\mathrm{Cr} \$ 1,50$ o $\mathrm{k}$, representará $\mathrm{Cr} \$ 15,15$ no total, o que ainda é econômico.

Concluimos que para frangos R. I. R. e com uma ração de base semelhante o período ideal de engorda será de 12 dias podendo prolongar-se, no máximo por mais 4 dias sem grande inconveniente econômico. Como o criador não pode sempre dispor dos frangos em dia certo, êle deverá fixars êsses limites, mínimo de 12 e máximo de 16 dias para a venda de seus frangos a pêso. 
A percentagenm de aumento cai bruscamente a partir dos 12 dias e permanece mais ou menos constante por três períodos.

GRAFICO I dias $\begin{array}{llllllllll}4 & 6 & 8 & 10 & 12 & 14 & 16 & 18 & 20 & 22\end{array}$

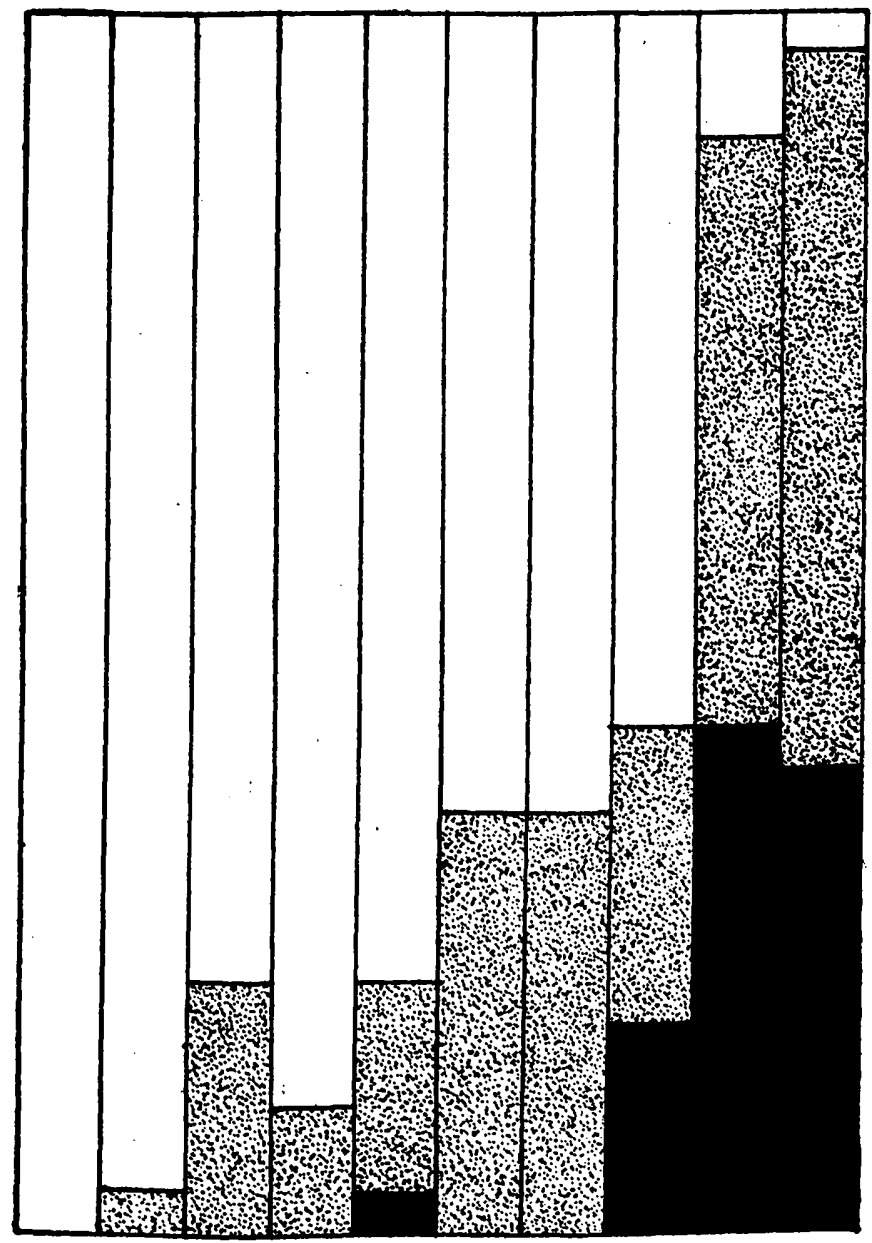

DIMINUIRAM ESTACIONARAM AUMEMTARAM 
A inspeção do Quadro II onde figuram os aumentos de pêso, por cento em 12 dias e 22 dias, permite verificar-se que, duma maneira geral, e considerado cada frango individualmente, o aumento de pêso nesse intervalo de 10 dias é pouco apreciável.

O exame do Gráfico I, que se segue, mostra claramente que o criador deve escolher entre 12 e 16 dias. Depois do décimo segundo dia até o décimo sexto, 10 frangos estacionaram seu pêso e só 19 aumentaram. Após 16 dias os frangos já começam a perder pêso : 5 entre 16 e 18 dias, 12 entre 18 e 20 dias e 11 entre 20 e 22 dias.

\section{RESUMO E CONCLUSŐES}

Os AA. levaram a efeito uma experiência com 29 frangos da raça Rhode I. Red, que foram submetidos a um regime de engorda em gaiolas, com uma ração contendo aproximadamente $17 \%$ de proteina bruta, com o intuito de determinar o número ótimo de dias, necessário para o acabamento da operação.

Os dados conseguidos e expressos nos quadros I e II e no Gráfico I, permitiram verificar que em 12 dias conseguia-se um aumento de 443 gs., correspondendo a $25,4 \%$ do pêso inicial, aos 14 dias 483 gs., correspondendo a $27,7 \%$ do pêso inicial, o que é pouco menos do pêso final alcançado em 22 dias, que corresponde ao aumento médio de 521 gs., representando $30 \%$ do pêso inicial.

Um Gráfico construido com os dados obtidos mostra que houve uma paralisação de crescimento de 10 frangos no período compreendido entre o $12^{\circ}$. e o $16^{\circ}$. dia de tratamento e que, a partir desta data começou a verificar-se uma paralisação cada vez mais crescente acompanhada mesmo de uma diminuição de pêso que atingiu 5 frangos aos 18 dias, 12 aos 20 dias e 11 aos 22 dias.

Entrando em considerações econômicas, demonstra que ainda é vantajoso levar essa engorda até os 16 dias, embora o aumento máximo de pêso se verifique até 12 dias.

\section{ABSTRACT}

This paper deals with an experiment to determine the optimum period (number of days) in fattening chickens. Thirty chickens R. I. R. were numbered, weighed and feeded in crate, with one standard ration (17\% crude protein). 
The chickens were weighted every two days and the results obtained indicate the optimum is reached between 12 and 16 days of feeding.

It was observed that after 16 days the weights stop or decrease progressively as showed by the Grafic I.

\section{BIBLIOGRAFIA}

1 - TORRES, A. P. e TRIVELIN, 1949 - Experiencias de engorda de frangos, I - in Anais da E. S. A. L. Q. - U. S. P., 6: 127, Piracicaba, E. de São Paulo.

2-JULL, M. A. e MAW, W. A., 1923 - Experimental results on fat Chickens. Poultry Science, 2:99.

3-EWING, W. R., 1951 - Poultry Nutrition, 99, South Passadena, California. 


$$
\text { , }
$$

